\title{
AC 2007-472: FROM TOOTSIE ROLLS TO COMPOSITES: ASSESSING A SPECTRUM OF ACTIVE LEARNING ACTIVITIES IN ENGINEERING MECHANICS
}

\section{Julie Linsey, University of Texas-Austin}

JULIE LINSEY is a Ph.D. candidate in the Mechanical Engineering Department at The University of Texas at Austin. Her research focus is on systematic methods and tools for innovative and efficient conceptual design with particular focus on design-by-analogy. Contact:julie@linseys.org

\section{Austin Talley, University of Texas--Austin}

AUSTIN TALLEY is a graduate student in the Mechanical Engineering Department at The University of Texas at Austin. His research focus is in design methodology and engineering education. He received his B.S. from Texas A\&M University. He previously worked for National Instruments Corporation. Contact Austin@talleyweb.com

\section{Daniel Jensen, U.S. Air Force Academy}

DAN JENSEN is a Professor of Engineering Mechanics at the U.S. Air Force Academy. He received his B.S., M.S. and Ph.D. from the University of Colorado at Boulder. He has worked for Texas Instruments, Lockheed Martin, NASA, University of the Pacific, Lawrence Berkeley National Lab and MacNeal-Schwendler Corp. His research includes development of innovative design methodologies and enhancement of engineering education.

\section{Kristin Wood, University of Texas-Austin}

KRISTIN WOOD is the Cullen Trust Endowed Professor in Engineering at The University of Texas at Austin, Department of Mechanical Engineering. Dr. Wood's current research interests focus on product design, development, and evolution. The current and near-future objective of this research is to develop design strategies, representations, and languages that will result in more comprehensive design tools, innovative manufacturing techniques, and design teaching aids at the college, pre-college, and industrial levels. Contact:wood@mail.utexas.edu.

\section{Kathy Schmidt, University of Texas-Austin}

KATHY J. SCHMIDT is the Director of the Faculty Innovation Center for the College of Engineering at the University of Texas at Austin. In this position, she promotes the College of Engineering's commitment to finding ways to enrich teaching and learning. She works in all aspects of education including design and development, faculty training, learner support, and evaluation.Contact k.schmidt@mail.utexas.edu

\section{Rachel Kuhr, University of Texas-Austin}

RACHEL KUHR is a undergraduate student in the Mechanical Engineering Department at The University of Texas at Austin Contact rachelkuhr@mail.utexas.edu

\section{Saad Eways, Austin Community College}

SAAD EWAYS is presently professor of Physics and Engineering and Assistant Dean of Math and Science at Austin Community College (ACC) where he teaches courses in both physics and engineering. He served as Department Head from 96-97 and Assistant Dean of Math and Science from 97-01. Dr. Eways received his Ph.D. in physics from the University of Texas at Austin. He received an M.S. in Nuclear Engineering and an M.S. and a B.S. in Electrical Engineer from the University of Illinois in Urbana-Champaign. Dr. Eways is very interested in improving student retention, increased student success and better and more efficient ways to teach science. 


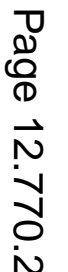




\title{
From Tootsie Rolls to Composites: Assessing a Spectrum of Active Learning Activities in Engineering Mechanics
}

Keywords: Active learning, hands-on activities, learning styles, Myers-Briggs

\begin{abstract}
$\underline{\text { Abstract }}$
The introduction of active learning exercises into a traditional lecture has been shown to improve student learning. Hands-on learning opportunities in labs and projects provide a primary approach in the active learning toolbox. This paper presents a series of innovative hands-on active learning activities for mechanics of materials topics. These activities are based on a Methodology for Developing Hands-on Active Learning Activities, a systematic approach for efficient and effective activity development, and were robustly evaluated at three institutions of higher learning. These institutions include a research university (The University of Texas, Austin), a four-year primarily teaching institution (The US Air Force Academy) and a community college (Austin Community College in Austin Texas). Seven of the twenty-eight activities have been rigorously evaluated to date. Evaluation consisted of a variety of measures, including student opinion surveys, focus groups, pre/post activity quizzes, exam questions and a concept inventory. In addition, demographic information, student learning styles and MyersBriggs Personality were measured and are correlated to the student evaluation measures. Data from over 150 students is summarized and insights gained are discussed. In general, students are excited about the hands-on activities in lecture, and they believe the activities enhance their learning. The majority of the assessment data also shows that the active learning activities enhance students' understanding of the material. While these general findings exist, students' opinions of the activities do vary with learning styles, institutions and their general understanding in the course. Learning styles, personality type, and perception of performance in the class all have influence on the students' opinions of the activities and will be measured further in future activity development and evaluation.
\end{abstract}

\section{Introduction and Motivation}

Active learning approaches improve students' overall learning ${ }^{1}$. There is considerable literature that addresses the advantages of using hands-on experiences in an engineering curriculum ${ }^{2-15}$. Although the importance of active learning activities is well recognized, little formal guidance in a systematic approach for development exists ${ }^{16}$. Many experts believe that a systematic approach for research into how we educate engineers is needed to provide long-lasting improvement in engineering education ${ }^{17-19}$. The overarching focus of our current research is to design, develop, assess, and implement Active Learning Products (ALPs) that improve the student learning processes and environment. ALPs are activities, such as hands-on exercises, thought experiments, forensic investigations, physical measurements, interactive multimedia exercises, and design applications, that enhance student learning across learning styles and personality types.

This paper presents data on the assessment of ALPs at multiple higher education institutions (The University of Texas, Austin [UT], The US Air Force Academy [USAFA] and Austin Community College [ACC] ). To assess the ALPs for continual improvement, we seek to answer the following educational research questions:

- Question 1: Are the ALPs effective for improving learning?

- Question 2: Are the effects of the ALPs different, based on student characteristics? 
- Question 3: What measures are important for a robust assessment strategy for the evaluation of questions 1 and 2?

This paper begins with a brief overview of the methodology used to develop the ALPs and then describes the ALPs being evaluated in this paper. The student handouts and professor guides for ALPs, created as part of the research, are available at the website http://www.me.utexas.edu/ mechmat/. Next details of the assessment method are given followed by the results relevant to each of the research questions. We end our discussion with an eye toward the future of ALPs.

\section{Innovative Mechanics of Materials Activities}

The activities evaluated are Active Learning Products (ALPs) developed to improve student's ability to understand mechanics of materials concepts. ALPs are based on enhancing learning through the use of hands-on and student-driven learning experiences. Twenty eight ALPs have been created as part of this work. Figure 1 shows the concise methodology used to guide the development of ALPs ${ }^{20}$. This Active Learning Product Design Methodology can also be used for design of ALPs for other technical topics. The methodology begins with understanding the educational goals, generating ideas, systematic selection of ideas, and finally implementation and evaluation of the newly-created ALP (Figure 1). This methodology also seeks to relate varied student personality types and learning styles to active learning. This is done as a subset of the "evaluation" step. ALPs are categorized into themes, such as hands-on exercises, thought

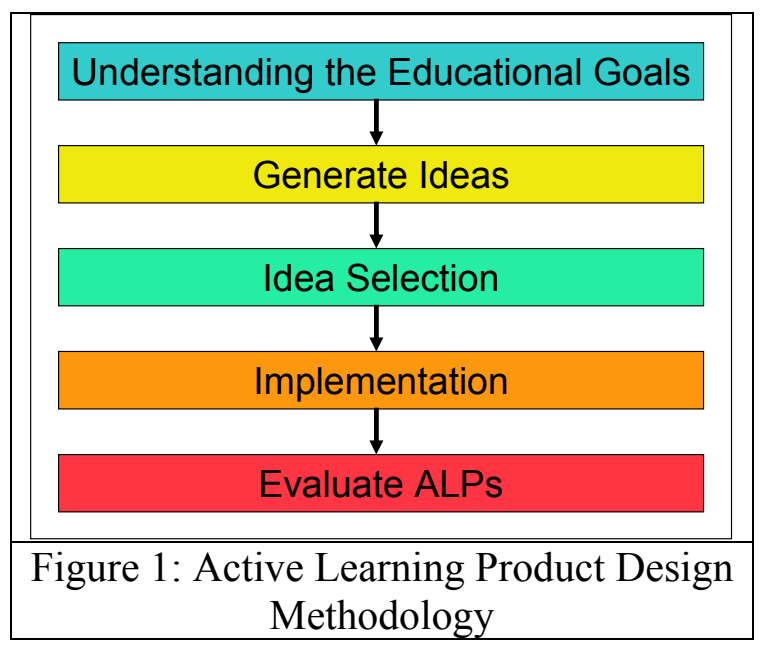
experiments, forensic investigations, physical measurements, multimedia exercises, and design applications. Currently, twenty-eight ALPs for mechanics of materials have been created across these themes. The seven ALPs evaluated in this paper are described in the following sections, 2.1 and 2.2, and focus on the themes of hands-on and multimedia exercises. A complete set of ALP materials including student worksheets, detailed professor notes and supporting material, are available at the Active Learning for Mechanics of Materials website (http://www.me.utexas.edu/ mechmat/).

\subsection{Exemplary Hands-on ALPs}

\subsubsection{Brittle and Ductile Failure}

The "Brittle and Ductile Failure" ALP seeks to develop a deeper conceptual understanding of maximum stress planes, failure and their relationship to the material type. Each student receives a piece of chalk and two Tootsie Rolls. Each student twists the piece of chalk and a Tootsie Roll causing torsional failure (Figure 2). A second piece of chalk is also broken using a bending load. The student compares the tactile and visual feedback to draw conclusions. The primary objective of this ALP is to help students experience stress transformations, basic failure theories, and differences between brittle materials (like chalk) that fail due to normal stress and ductile 
materials (like tootsie rolls) that fail due to shear stress. In this light, students are asked to explain the angles on the failure surface and relate them to predicted failure modes. The fact that the brittle chalk fails at a $45^{\circ}$ angle when in torsion specifically allows the student to visually and tactilely correlate this angle with the maximum normal stress surface. In the same light, the $90^{\circ}$ failure surface for the ductile tootsie roll in torsion is seen to correlate with the maximum shear surface. The professor's role in this and the other ALPs is to guide the students through the activity, to provide feedback and additional explanations as required. (See http://www.me.utexas.edu/ mechmat/ for a complete description of the ALP.)
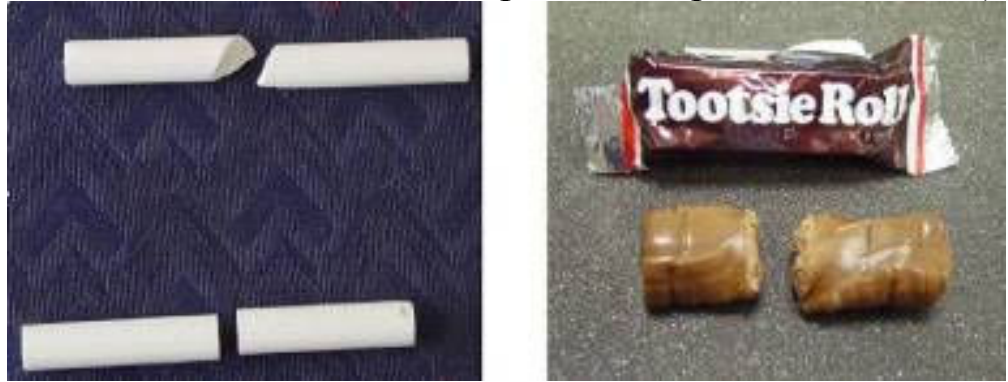

Figure 2: Failure modes of chalk in torsion (top) and bending (bottom) and Tootsie Roll in torsion.

\subsubsection{Directional Strength}

The "Directional Strength" ALP guides the students in obtaining hands-on experiences related to directional strength. The specific educational objective is for students to understand the directional nature of a material's strength and its effect on the observed failure plane. Students individually draw a square representing a stress element on two craft sticks. Next, the students load the craft sticks to failure in two different ways shown in Figure 3, applying end moments by bending the stick by hand and applying a point load to a simply supported beam. Next, the craft sticks are placed with supports parallel to the grain of the wood and again loaded to failure. The grain-directional nature of the properties of the wood can easily be felt as the fracture parallel to the grain is initiated with only a fraction of the force needed to initiate fracture across the grain.
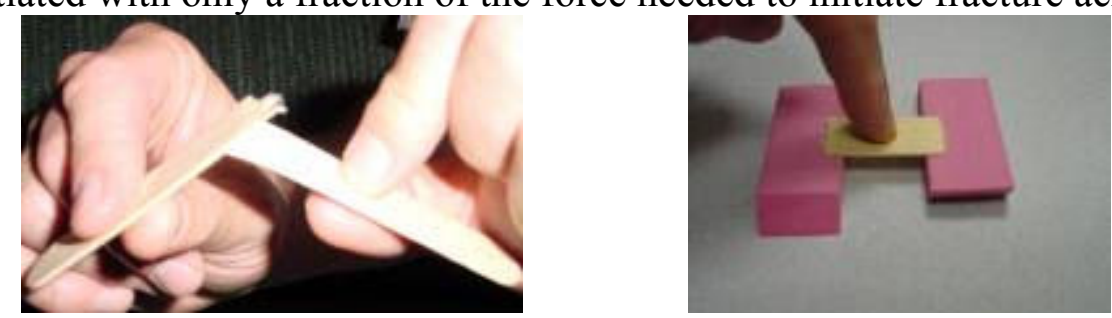

Figure 3: Loaded with end moments (left) and simply supported (right)

\subsubsection{Foam Rod}

The "Combined Loading Foam Rod" ALP addresses a three-part educational objective. The objective includes: 1) understanding the differences between normal and shear stresses, 2) relating the different kinds of stress to different loading scenarios and 3) visualizing the stress distributions through the cross section of the rod. The following ALP was created to allow students to visually and tactilely experience these three concepts.

Students were given a section of a flexible foam rod (Figure 4). Pipe insulation was used for this class; however, a "swimming pool noodle" could also be used. Each rod was 
approximately 10 inches long, with an outside diameter of 1.5 inches, and had three squares inscribed on its surface. In addition an axis was visible next to the blue square showing that the $\mathrm{X}$-axis is located down the long axis of the rod.

A pair of students was instructed to manipulate the beam first in axial loading, then bending, then torsion and then combinations of these loads as shown on the chart (Figure 5). Note that the chart that the students received did not have the information in the last 4 columns (Shape, $\sigma_{X}(\mathrm{y} / \mathrm{n}), \tau_{X Y}(\mathrm{y} / \mathrm{n})$ and Comments) filled in. The students were instructed to fill in that data. Recall that the objective of this activity includes providing students with tactile and visual information on what types of loading (and combinations of loading) create certain deformations of the stress elements. Therefore, it is critical that the students "feel" the type of loading that

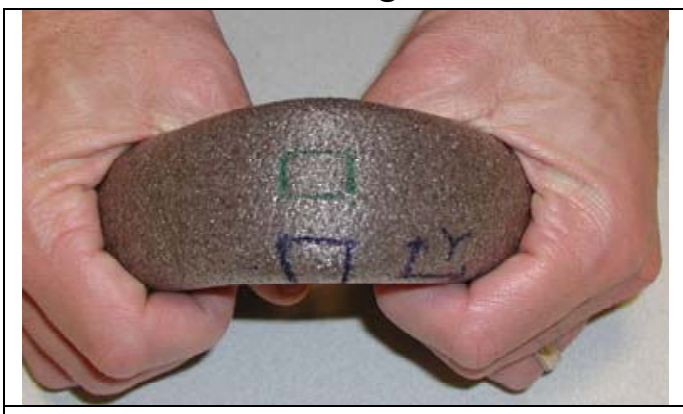

Figure 4: Foam Rod Deformation creates only normal stresses and simultaneously "see" that this does not cause angle changes in the stress elements. Alternately, they will "feel" loading that causes shear stress and "see" that this loading does change the stress element angels from their original $90^{\circ}$ values.

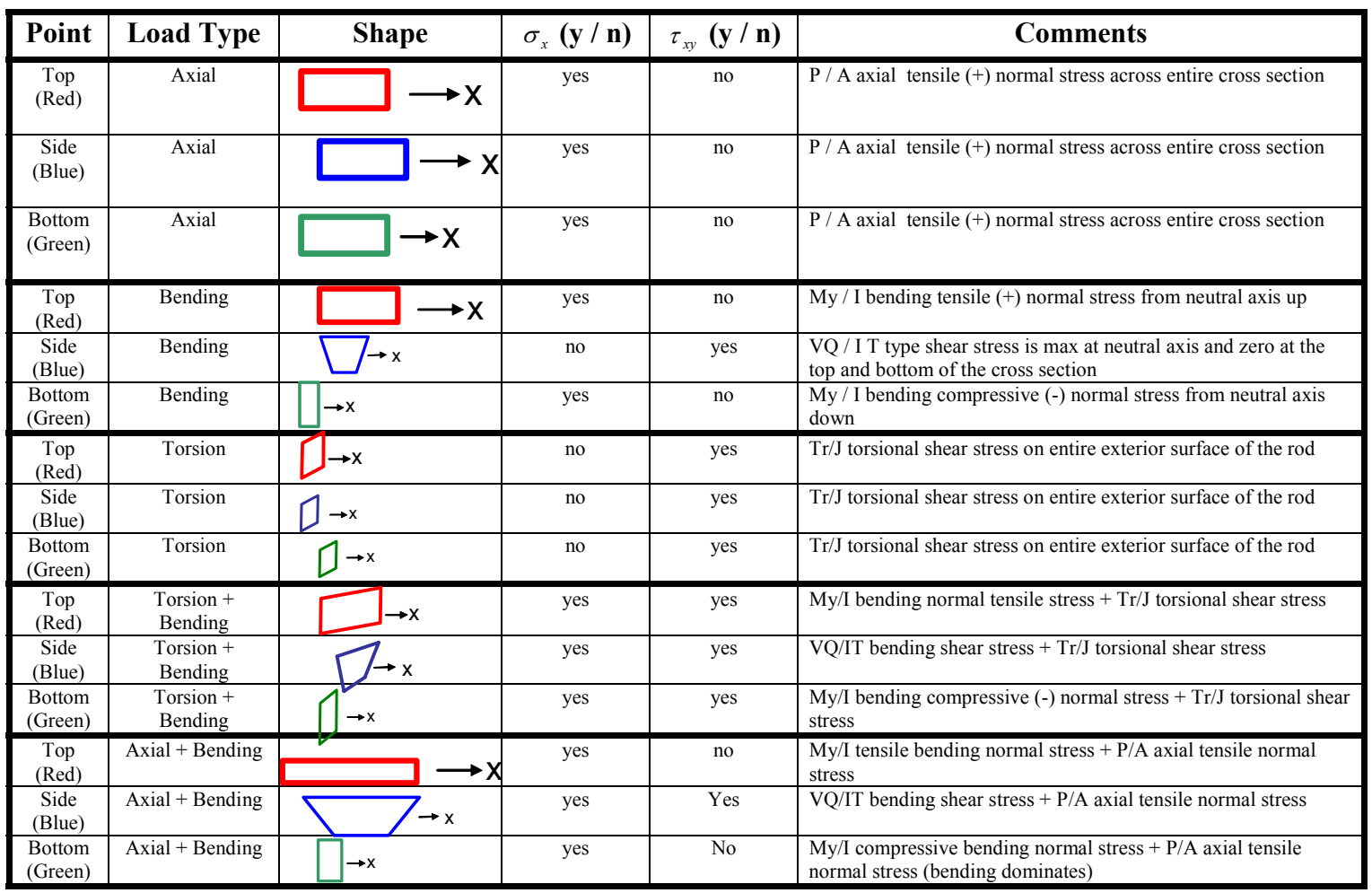

Figure 5: Completed Chart from the Foam Rod ALP

\subsubsection{Photoelastic Beam Bending}

The "Visualizing Stress Distributions in Photoelastic Beam Bending" ALP allows the student to explore, through visual and tactile feedback, different factors that affect bending stress and the internal stress states in bending members. The specific educational objective for this ALP is for 
students to demonstrate the ability to predict moment and normal stress distributions due to bending loads. This activity is an in-class ALP with groups of two to four students. The photo elastic box, shown in Figure 6, is made of simple wood chipboard with a metal retention bracket, polycarbonate plastic beam, and two circular polarized lenses to create a visible the stress pattern in the beam. Students attempt to predict what color contours will occur for a cantilever photoelastic beam under light and heavy transverse loads. The students then bend the beams, observe the color contours, and compare them to their predictions. The color contours help students visualize the neutral axis as well as the moment distributions for the cantilevered bending problem.

\subsubsection{Identify Items under Combined Loads}

The "Identify Items under Combined Loads" ALP has as its objective for students to demonstrate the ability to identify everyday devices and structures that include combined loading, identify the exact types of loading and produce a correct free body diagram (FBD) for the system. This ALP was suggested as an individual

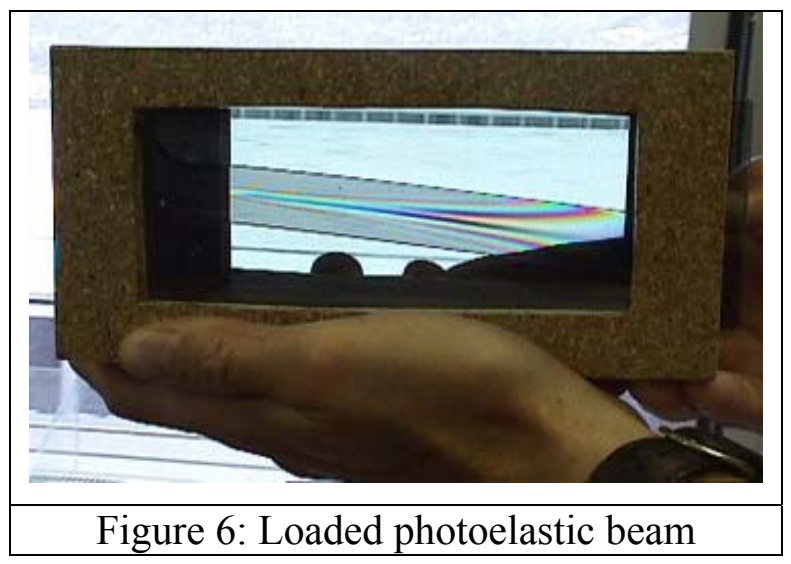
homework assignment. The students identify everyday devices and structures that have combined loads applied to them. The students then complete a table of information including component, type of loading, support model, and free body diagram for each item shown in Table 1. Examples are found in kitchen appliances, hand tools, power tools, children's toys, sports equipment, homes, local bridges and more. The students them complete the table for the items they have found and bring it back to class for group discussion.

Table 1: Example of Combined Loading Worksheet

\begin{tabular}{|c|c|c|c|}
\hline $\begin{array}{c}\text { Device/ Structure } \\
\text { Screw while it is being } \\
\text { driven into a piece of } \\
\text { wood }\end{array}$ & Component & Type of Loads & Axial, Torsion \\
\hline $\begin{array}{c}\text { Road Sign when the } \\
\text { wind is blowing }\end{array}$ & Sign Post & Bending, Axial & \\
\hline
\end{tabular}




\subsection{Exemplary Visual Mechanics of Materials (Multimedia)}

\subsubsection{VisMOM Bending and Combined Loading Modules}

VisMOM (for Visual Mechanics of Materials) is a suite of interactive multimedia covering many of the core concepts in a standard Mechanics of Materials course. VisMOM contains hundreds of pictures, sketches, graphics, example problems and design problems all geared toward providing a visually rich, interactive environment for students to experience Mechanics of Materials in a conceptual manner (Figure 7 and Figure 8). The VisMOM software gives global overviews of the topics in each section and then provides students with example problems and interactive visuals including design problems. The VisMOM software can be downloaded at http://www.me.utexas.edu/ mechmat/software.htm. For this activity students were instructed to read and work through the bending and combined loading modules.

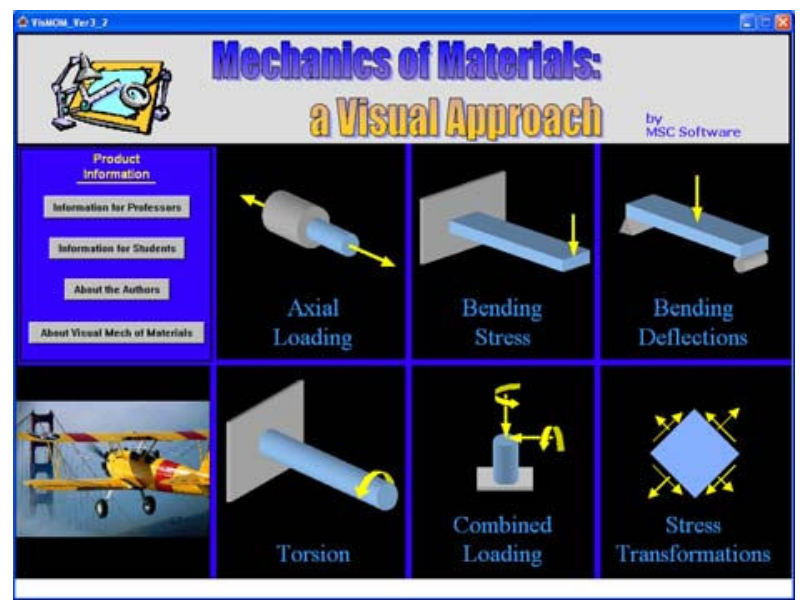

Figure 7: VisMOM modules, a visual

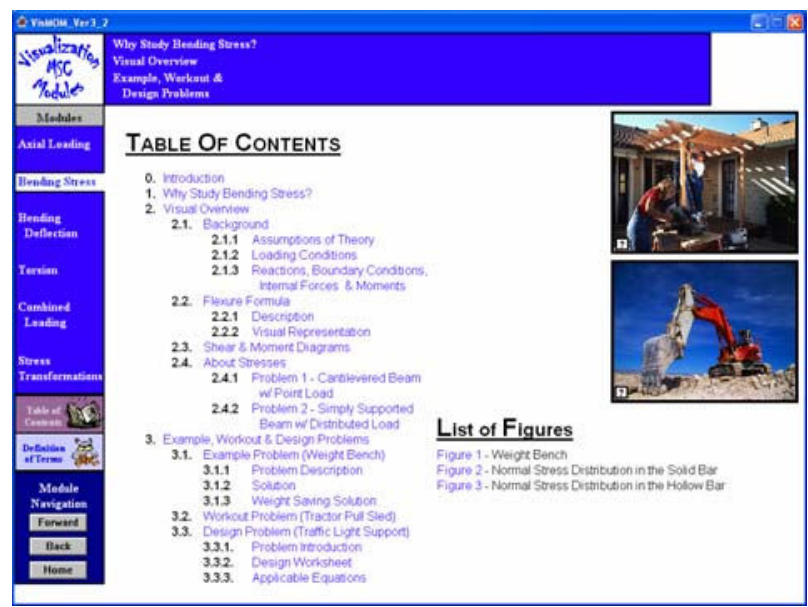

Figure 8: Overview of a module's contents approach to teaching mechanics of materials

\subsubsection{VisMOM Traffic Light Beam Bending}

In this ALP the students were asked in groups to design a beam to support a traffic light specifically taking into account minimizing cost, safety factors, beam weight, and stress level in the beam. The exercise utilizes the VisMOM software to allow the students to interactively select material properties and cross section geometry. With the additional input of a free body diagram and other information the VisMOM software provides the students with the resulting model weight, safety factor, and cost (Figure 9).

\subsubsection{VisMOM Mohr's Circle}

For this ALP, the VisMOM software creates an interactive Mohr's circle where the students can manipulate inputs and instantly see the effect on the stress planes. Students often feel intimidated by the creation of the

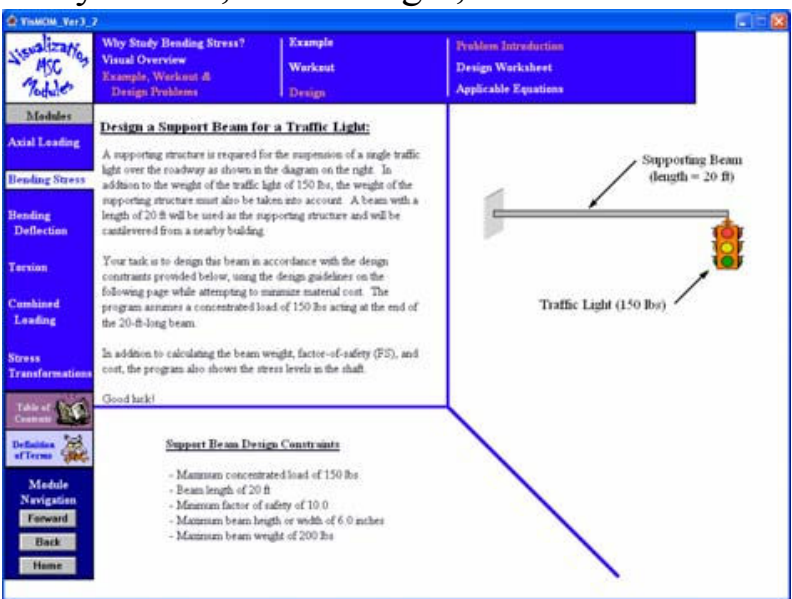

Figure 9: Traffic Light Beam Bending VisMOM 
Mohr's circle. The specific educational objective of this ALP is for students to demonstrate an understanding of the relationship between Mohr's circle, the stress elements and principle stresses (Error! Reference source not found.).

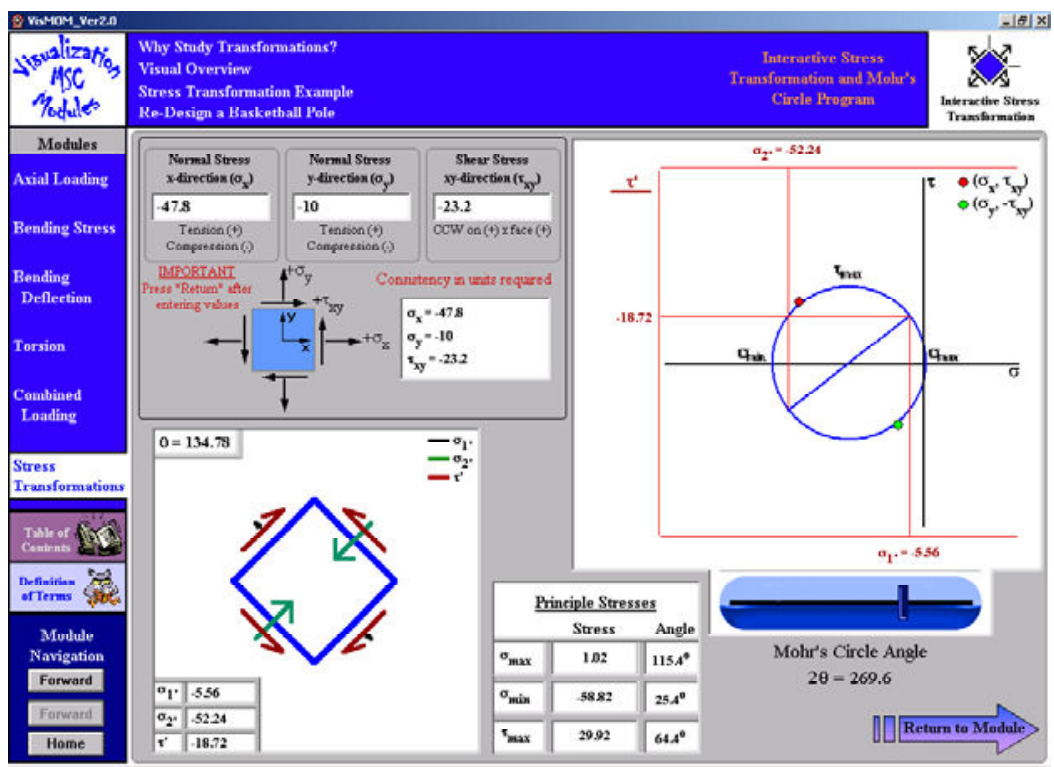

Figure 10: Mohr's Circle in VisMOM software

\section{Method for the Evaluation of the ALPs}

A total of seven of the twenty-eight created activities were evaluated. The activities were evaluated at three different higher-education schools over four semesters. A combination of student opinion surveys, a concept inventory, pre/post activity quizzes and a focus group were used to evaluate the ALPs. In addition, students' personality types using Myers-Briggs Personality inventory ${ }^{21,22,23}$, learning styles using the Felder-Soloman's Index of Learning Styles $^{24}$ and demographic information were also recorded and correlated with the other assessment information. Demographic information included major, reason for taking the class, race, gender, and G.P.A. Students were also asked what grade they expected to receive in the course. Table 2 summarizes the activities that were evaluated and the assessment measures used for each activity. The following sections begin with a summary of the demographics, distribution of students' personality and learning styles and then shows the assessment results for each activity. 
Table 2: Overview of Activity Assessment

\begin{tabular}{|c|c|c|c|c|c|c|}
\hline \multirow{2}{*}{\begin{tabular}{r||} 
Semester \\
School \\
\end{tabular}} & \multicolumn{2}{|c|}{ Fall 05} & \multicolumn{2}{|c|}{ Spring 06} & \multirow{2}{*}{$\begin{array}{c}\text { Sum } 06 \\
\text { UT } \\
\end{array}$} & \multirow{2}{*}{$\begin{array}{ll}\text { Fall } 06 \\
\text { USAFA } \\
\end{array}$} \\
\hline & \begin{tabular}{|l|l} 
USAFA \\
\end{tabular} & $\mathrm{ACC}$ & UT & USAFA & & \\
\hline Course & \begin{tabular}{|l} 
Machine \\
Elements
\end{tabular} & $\begin{array}{c}\text { Mechanics of } \\
\text { Materials } \\
\end{array}$ & $\begin{array}{l}\text { Machine } \\
\text { Elements } \\
\end{array}$ & $\begin{array}{c}\text { Basic } \\
\text { Mechanics }\end{array}$ & \begin{tabular}{|l|} 
Machine \\
Elements \\
\end{tabular} & \begin{tabular}{|c|} 
Mechanics \\
of Materials
\end{tabular} \\
\hline Activities and Topics & & & $\begin{array}{c}\mathrm{C}, \mathrm{D}, \mathrm{M}, \mathrm{L}, \\
\mathrm{F}\end{array}$ & $\mathrm{D}, \mathrm{M}, \mathrm{L}$ & $\mathrm{D}, \mathrm{M}, \mathrm{L}$ & $\mathrm{D}, \mathrm{M}, \mathrm{L}$ \\
\hline \multicolumn{7}{|l|}{ Bending-Flexure } \\
\hline \multicolumn{7}{|l|}{5.1 Internal Force \& Moment } \\
\hline $\begin{array}{l}\text { 5.1b VisMOM Traffic Light Beam } \\
\text { Bending }\end{array}$ & & & & $\mathrm{S}, \mathrm{D}$ & $\mathrm{Q}, \mathrm{S}, \mathrm{D}$ & $\mathrm{S}, \mathrm{Q}, \mathrm{D}$ \\
\hline \multicolumn{7}{|l|}{ 5.2 Find items under bending } \\
\hline \multicolumn{7}{|l|}{$\begin{array}{l}5.3 \text { Bending members with common } \\
\text { cross-sections }\end{array}$} \\
\hline \multicolumn{7}{|l|}{5.4 Feel craft sticks bending } \\
\hline $\begin{array}{l}\text { 5.5 Stress Opticon: Bending stress } \\
\text { distribution }\end{array}$ & & & & & & S, Q, D \\
\hline \multicolumn{7}{|l|}{ 5.6 Quantify flexure in a craft stick } \\
\hline \multicolumn{7}{|l|}{ 5.7 Stress Opticon: simple support } \\
\hline 5.8 Photoelastic beam bending & & & & $\mathrm{S}, \mathrm{D}$ & & $\mathrm{S}, \mathrm{Q}, \mathrm{D}$ \\
\hline \multicolumn{7}{|l|}{ Stress Transformation } \\
\hline 7.1 Directional Strength (Craft Stick) & & $\mathrm{S}$ & & & & \\
\hline \multicolumn{7}{|l|}{$\begin{array}{l}\text { 7.2 Directional Orientation in } \\
\text { Structures }\end{array}$} \\
\hline 7.3 Photoelasticity: Beam with holes & & & & & & $\mathrm{S}, \mathrm{Q}, \mathrm{D}$ \\
\hline \multicolumn{7}{|l|}{ 7.4 Matching loads and failure planes } \\
\hline 7.5 Brittle and Ductile Failure & & $\mathrm{S}$ & $\mathrm{S}, \mathrm{D}$ & & $\mathrm{S}, \mathrm{D}$ & \\
\hline 7.6 VisMOM Mohr's Circle & & & $\mathrm{S}, \mathrm{D}$ & & $\mathrm{S}, \mathrm{D}$ & $\mathrm{S}, \mathrm{Q}, \mathrm{D}$ \\
\hline \multicolumn{7}{|l|}{ Combined Loading } \\
\hline $\begin{array}{l}\text { 9.1 Identify items under combined } \\
\text { loads }\end{array}$ & & & & $\mathrm{S}, \mathrm{Q}$ & $\mathrm{S}, \mathrm{Q}, \mathrm{D}$ & $\mathrm{S}, \mathrm{Q}, \mathrm{D}$ \\
\hline \multicolumn{7}{|l|}{9.2 Visualizing a stress element } \\
\hline 9.2a Foam rod & $\mathrm{S}$ & & $\mathrm{S}, \mathrm{D}$ & $\mathrm{S}, \mathrm{Q}$ & $\mathrm{S}, \mathrm{Q}, \mathrm{D}$ & $\mathrm{S}, \mathrm{Q}, \mathrm{D}$ \\
\hline \multicolumn{7}{|l|}{9.3 Visualizing stress concentrations } \\
\hline \multicolumn{7}{|l|}{9.4 Observation of failure planes } \\
\hline \multicolumn{7}{|l|}{9.5 Foam beam and comparison chart } \\
\hline 9.6 VisMOM software Mohr's Circle & & & $\mathrm{S}$ & & & \\
\hline \multicolumn{7}{|l|}{ Torsion } \\
\hline \multicolumn{7}{|l|}{ 11.1 Find components under torsion } \\
\hline \multicolumn{7}{|l|}{$\begin{array}{l}11.2 \text { Design and Manufacturing of } \\
\text { Torsion Beams }\end{array}$} \\
\hline \multicolumn{7}{|l|}{ Fatigue } \\
\hline \multicolumn{7}{|l|}{ 12.1 Find fatigue loads } \\
\hline \multicolumn{7}{|l|}{ 12.2 Fatigue failure of a wood beam } \\
\hline \multicolumn{7}{|l|}{ 12.3 Fatigue failure of an eraser } \\
\hline 12.4 Will the street signal pole fail? & & & & & & \\
\hline
\end{tabular}

Legend: $\mathrm{C}=$ Pre/Post Concept Inventory, $\mathrm{D}=$ Activity Linked to Demographic Data, $\mathrm{F}=$ Focus Group, LS= Felder-

Solomon's Index of Learning Styles, M=Myers-Briggs Personality Inventory, S=Survey, Q=Pre/Post Quiz 


\subsection{Myers-Briggs Type Indicator Personality Inventory}

The Myers-Briggs Type Indicator (MBTI) includes four categories of preference ${ }^{21,22,23}$ (Table 3). Although MBTI categorization is well-established, its use as an indicator of the way people learn is far less common. The second of the four categories provides insight into how a person processes information. Those who prefer to use their five senses to process the information (sensors) are contrasted with those who view the intake of information in light of either its place in an overarching theory or its future use (intuitors). This sensor vs. intuitor category is seen by most researchers to be the most important of the four categories in terms of implications for

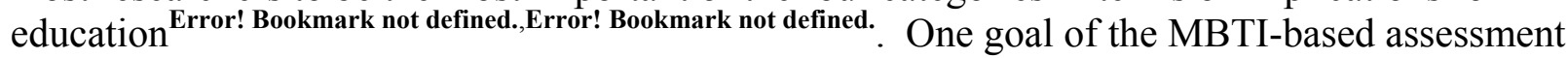
is to determine if the ALPs favor one MBTI type over another. Ideally, the use of the ALPs would span the MBTI types without preference.

Table 3: Overview of MBTI

\begin{tabular}{|c|c|c|c|}
\hline \multicolumn{5}{|c|}{ Manner in Which a Person Interacts With Others } \\
\hline E & Focuses outwardly. Gains energy from others. & Focuses inwardly. Gains energy from cognition & I \\
\hline \multicolumn{5}{|c|}{ MXTROVERSION } & INTROVERSION \\
\hline \multicolumn{5}{|c|}{ Manner in Which a Person Processes Information } \\
\hline S & Focus is on the five senses and experience. & Focus is on possibilities, use, big picture. & N \\
\hline \multicolumn{5}{|c|}{ SENSING } & INTUITION & F \\
\hline T & Focuses on objective facts and causes \& effect. & Focuses on subjective meaning and values. & FEELING \\
\hline \multicolumn{5}{|c|}{ THINKING } & Panner in Which a Person Comes to Conclusions \\
\hline J & Focus is on timely, planned decisions. & Focus on process oriented decision-making. & P \\
\hline \multicolumn{5}{|c|}{ JUDGEMENT } & PERCEPTION \\
\hline
\end{tabular}

\subsection{Felder-Soloman's Index of Learning Styles}

Felder- Soloman's Index of Learning Styles ${ }^{24}$ are composed of four dimensions (active/reflective, sensing/intuitive, visual/verbal, and sequential/global) (Table 4). Richard M. Felder and Linda K. Silverman formulated this as a way of focusing on assessing the learning style of an individual. This index helps the instructor determine if an ALP has the same effect on all learning styles. As an example, instructors' teaching styles often favor sensing over intuitive learning styles or vice versa. The goal of this index is to assist instructors to create ALPs that impact all student learning styles equally.

Table 4: Felder-Soloman's Index of Learning Styles

\begin{tabular}{|c|c|}
\hline ACTIVE & REFLECTIVE \\
\hline $\begin{array}{c}\text { Doing something active with it --discussing, } \\
\text { applying, or explaining it to others }\end{array}$ & Thinking about it quietly first \\
\hline SENSING & INTUITIVE \\
\hline Learning facts & Discovering possibilities and relationships \\
\hline VISUAL & VERBAL \\
\hline $\begin{array}{c}\text { See--pictures, diagrams, flow charts, time lines, } \\
\text { films, and demonstrations }\end{array}$ & Words--written and spoken explanations \\
\hline SEQUENTIAL & GLOBAL \\
\hline Gain understanding in linear steps & Learn in large jumps - suddenly "getting it." \\
\hline
\end{tabular}




\section{Assessment Results: Question 1}

Research question 1: Are the ALPs effective for improving learning?

This research question was assessed through pre- and post- ALP experience quizzes and surveys which were designed to measure the effects of the ALPs. Between fall 2005 and summer 2006 sixteen sets of surveys for seven different ALPs were collected from three academic institutions (The University of Texas, Austin [UT], The US Air Force Academy [USAFA] and Austin Community College [ACC]) (Table 2). During fall 2005, pre and post quiz data was measured for seven sections of classes at USAFA. The following are representative samples of the data sets.

\subsection{Assessment - Pre- and Post- ALP Experience Quizzes}

Quizzes were given to students before and after a concept was taught to assess learning. Two groups of students were compared. One group received traditional instruction (control group) whereas the other group received instruction that included the ALP (experimental group). Figure 11 shows that, overall, the experimental group experiences greater improvement in their quiz score than those in the control group. A t-test shows this is statistically significant $(\mathrm{t}=1.32, \mathrm{p}<0.1$

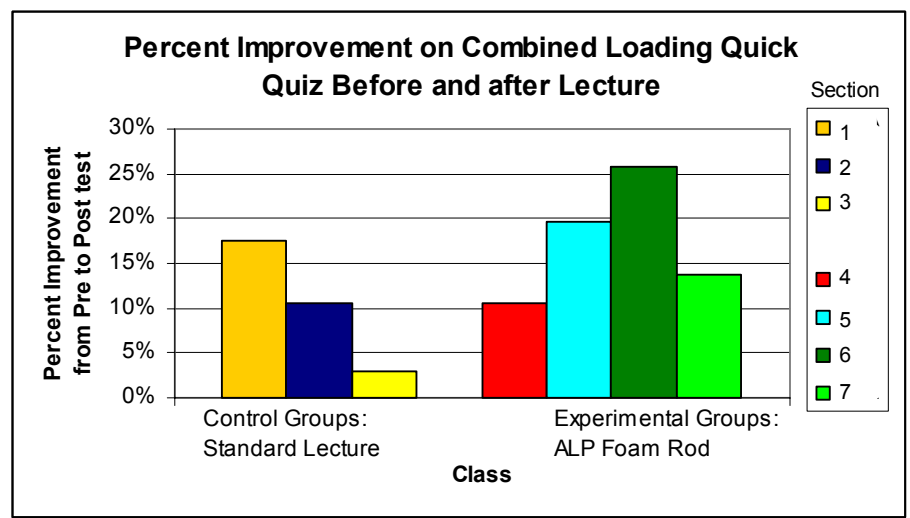

Figure 11: Foam Rod ALP: Percent Improvement by Class Section USAFA Spring 2006 control group $n=62$, experimental group $n=91$ ). Note that there is a significant variation in the quiz score improvement between the different sections of the course. The source of these variations include the students in the class, the time of day the class was offered and other yet to be identified sources. The significant aspect from this data is that the average improvement of the experimental group was greater than the control group, indicating students are learning more with the ALPs.

\subsection{Assessment - Surveys}

Motivation to learn is fundamental to successful learning. Student motivation was measured using surveys taken after the students experienced the ALPs. As shown in Figure 12 and Table 5, students at USAFA in the fall 2005 and spring 2006 semesters had similar scores between the semesters, but with a more skeptical response to the surveys than UT students. The surveys for the three semesters were very similar but not identical. The gaps in the data on Figure 12 occur when a question was not included in a particular survey. Overall, UT students scored the surveys much higher in all categories. Figure 13 gives a snapshot of one survey question. The figure shows the greater skepticism of USAFA students versus UT students and the overall trend in the surveys of a positive opinion of the ALPs. Although we do not have conclusive data, we hypothesize that the less enthusiastic response from the USAFA cadets may be due to the fact that the course where they experience the active learning is taken by all cadets regardless of 
major. Therefore, the majority of students in the class are not technical majors and thus may have a reduced interest in the content.

Table 5: Foam Rod Survey Questions

\begin{tabular}{|l|l|}
\hline 1 & This activity helped me understand the topic of "Combined Loading" better. \\
\hline 2 & $\begin{array}{l}\text { Personally manipulating the foam beam \& seeing the results was better than a } \\
\text { classroom demonstration done by the instructor. }\end{array}$ \\
\hline 3 & $\begin{array}{l}\text { I believe this activity was more effective than using class time for lecture with the } \\
\text { board. }\end{array}$ \\
\hline 4 & The activity was a waste of time. \\
\hline 5 & $\begin{array}{l}\text { This activity increased my interest in mechanics concepts (like axial, torsion and } \\
\text { bending). }\end{array}$ \\
\hline 6 & I believe this activity helped me prepare for the final exam. \\
\hline 7 & I liked doing this activity. \\
\hline
\end{tabular}

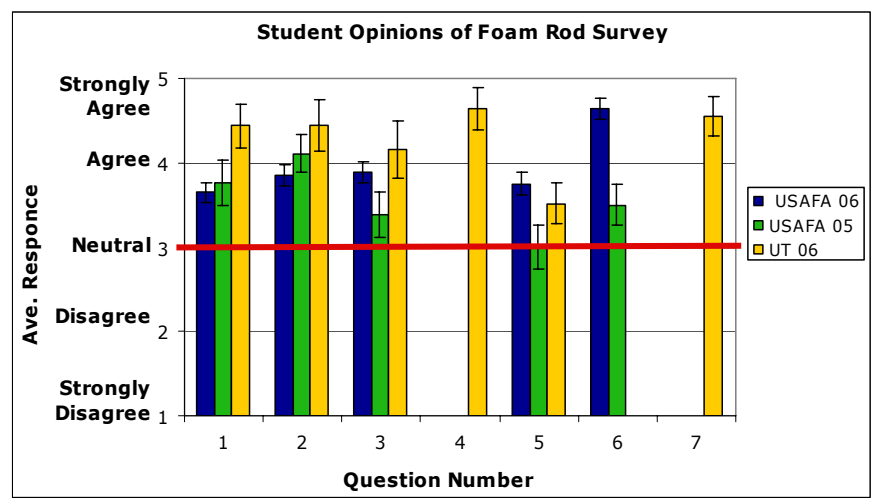

Figure 12: Foam Rod Survey Average Response USAFA Spring 06, Fall 05, \& UT Spring 06

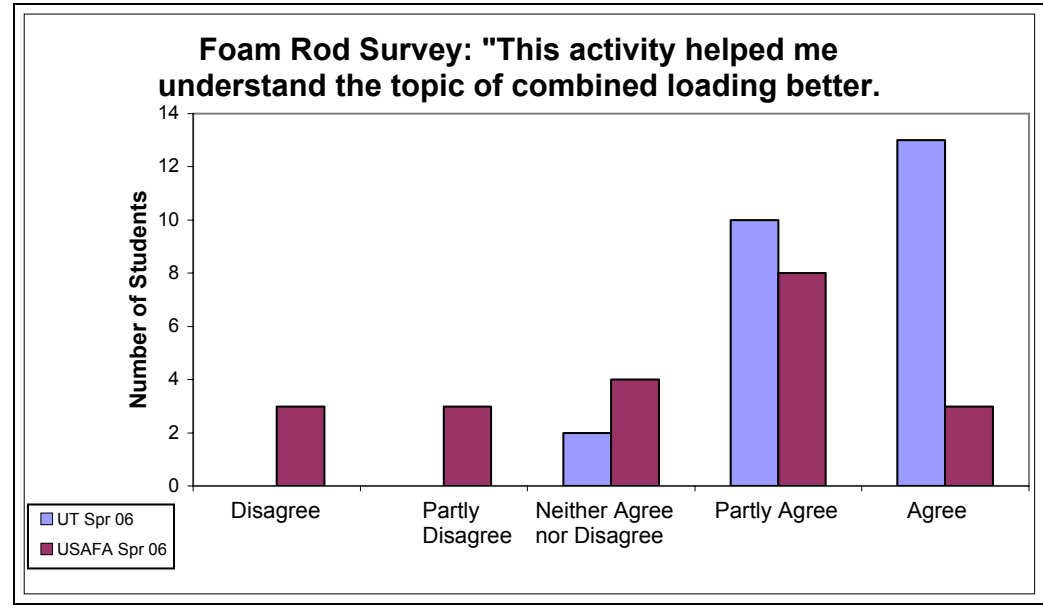

Figure 13: Foam Rod Survey "This activity helped me understand combined loading better."

The photoelastic beam bending ALP was evaluated at USAFA in spring 2006 with a total of 98 students across four class sections with three different professors. Each section had 
approximately 25 students. In general, students provided positive feedback about this activity (Table 6 and Figure 14). Most students liked executing the activity (question 10), felt like it was a good use of their time (question 8) and believed it improved their conceptual understanding of the topic (question 4). Students were indifferent if the activity would help them do better on homework or exams even though they felt this activity helped their conceptual understanding. As can be seen in Figure 15, some sections were clearly confused by the photoelastic beam activity. This indicates that the professor notes or the student handouts may need to be improved. From the survey results, it is likely that one of the professors was able to make the activity clear to the students. It is worth noting that most students felt having the photoelastic devices in their hands was better than only watching a demonstration in front of the class. The reasons for the differences between different sections could be differences in lectures, class time, student composition of section or a variety of other variables. More investigation is needed to determine the cause of this variation. The overall significance of this survey data is that students had a positive opinion of the ALPs in the classroom, liked doing the activity and believed it helped them understand the material.

\begin{tabular}{|l|}
\hline \multicolumn{1}{|c|}{ Table 6: Photoelastic Beam Bending Survey Questions } \\
\hline 1. This activity helped me understand the topic of "Bending" better. \\
\hline $\begin{array}{l}\text { 2. Personally seeing/touching the photoelastic device was better than a classroom } \\
\text { demonstration done by the instructor. }\end{array}$ \\
\hline 3. This activity will help me do bending homework problems. \\
\hline 4. This activity helped me understand bending in a conceptual manner. \\
\hline 5. This activity will help me on the next exam. \\
\hline 6.*This activity was confusing. \\
\hline $\begin{array}{l}\text { 7. I believe this activity was more effective than using class time for lectures or board } \\
\text { work. }\end{array}$ \\
\hline 8. *The activity was a waste of time. \\
\hline $\begin{array}{l}\text { 9. This activity increased my interest in mechanics concepts (like axial, torsion and } \\
\text { bending). }\end{array}$ \\
\hline 10. I liked doing this activity. \\
\hline
\end{tabular}
*reverse scored

Recall that the research question we are attempting to answer in this section is "are the ALPs effective for improving learning?". Overall, the results show that learning is improved by the ALPs. Students' are generally positive about the activities (as shown by the survey results) and the "before \& after" quick quiz results support the fact that learning is being improved. While we have only reported a portion of the large quantity of assessment data we have obtained, the remaining data supports the same general results. 


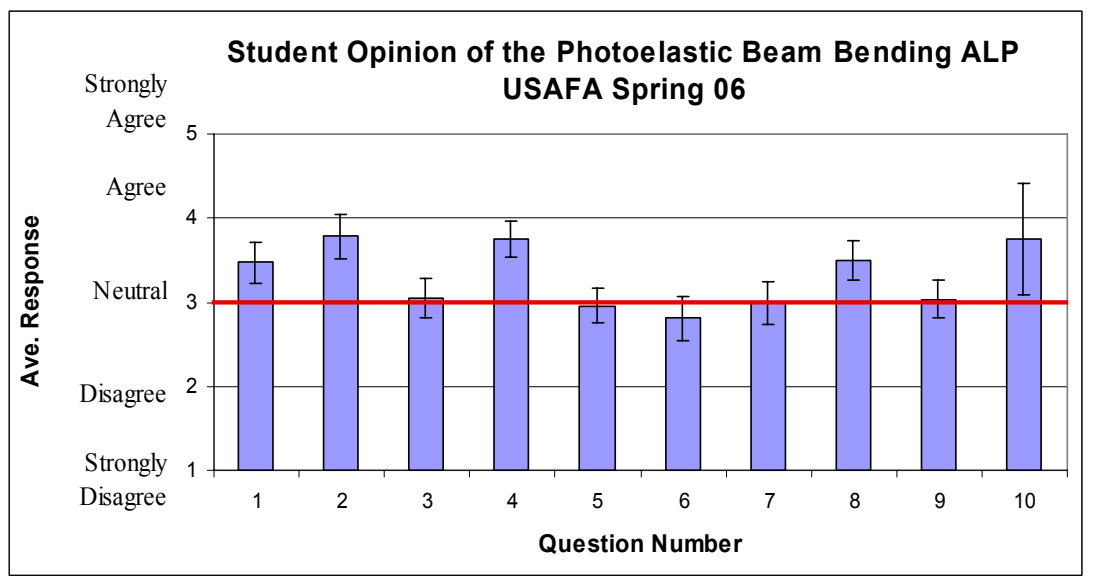

Figure 14: Student opinion of the photoelastic beam bending ALP. Each error bar is two standard errors $(n=96)$.

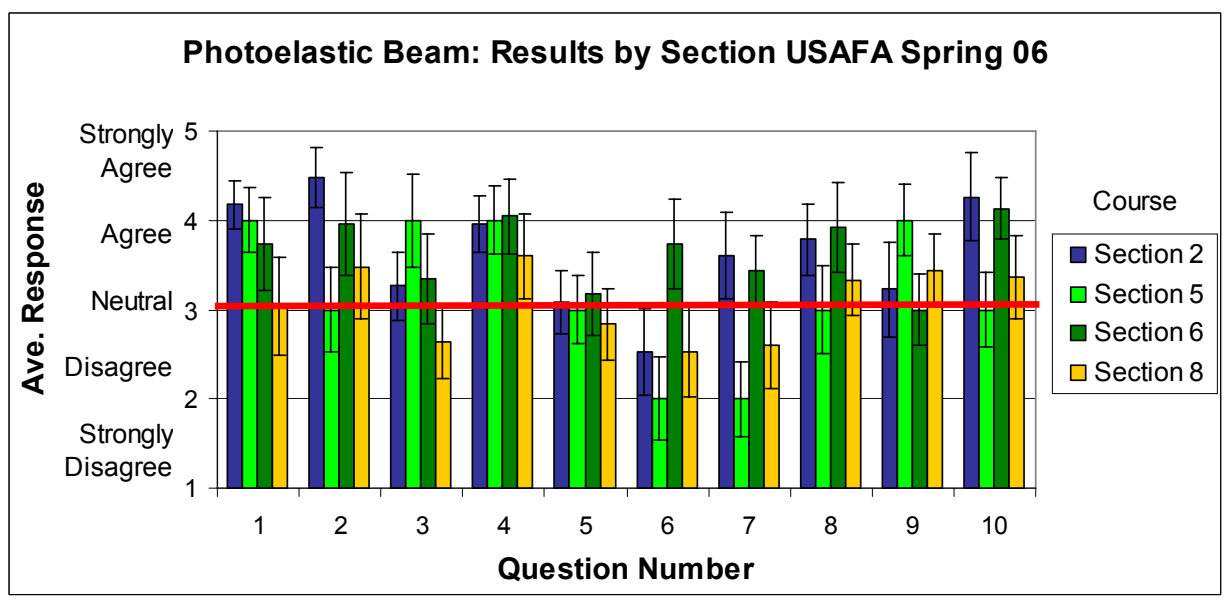

Figure 15: Student opinion of the photoelastic beam bending ALP by section ( $\mathrm{n} \approx 25$ per section).

\section{Assessment Results: Question 2}

Research question 2: Are the effects of the ALPs different based on student characteristics?

One of the overall goals when developing the ALPs has been to ensure that no category of students was given preference over another category. In particular, we endeavor to ensure that students who learn in different manners or process information in different manner are not given preference. Correlations between the effectiveness of the ALPs and other student characteristics are being investigated as well. Student characteristics assessed included perceived grade (a measured of perceived class performance), plans after graduation, overall G.P.A., FelderSoloman's Index of learning styles, and Myer-Briggs Type Indicator personality type. These were correlated to survey data of the ALPs. During spring and summer 2006 ten survey data sets were correlated with student characteristics (Table 2). The following are representative samples of the data sets. 


\subsection{Student Survey Results Correlated with Student Characteristics}

Students' opinions of the ALPs were correlated with their "expected grade in class", "career plans after graduation" and "overall G.P.A.". The student's expected grade was measured after approximately one month of class so this measure is likely an indication of how well the students felt they understood the material as they progressed through the class. No differences in opinion were observed as function of "career plans after graduation" or "overall G.P.A". For most survey questions there were no trends in correlation between expected grade and survey opinion. T-tests were used to evaluate statistical significance. In each graph the error bars are two standard errors. When the error bars do not overlap this represents just above a 95\% confidence that the two quantities are statistically different. Interestingly, for a few questions, the expected grades in the course did influence how positively the students rated an ALP (Figures 16-18). Ttests were used to evaluate statistical significance. In each graph the error bars are two standard errors. When the error bars do not overlap this represents just above a $95 \%$ confidence that the two quantities are statistically different.

Figures 16-18 show examples of the expected grade trending with survey questions. Expected grade and survey data for the photoelastic beam bending shows that students who did not feel they understood the material as well generally rated this activity more positively, and liked doing the activity than students who were expecting "A's" in the class. In Figure 16 and Figure 17, the trend is not statistically significant. In Figure 18 expected grade is correlated with VisMOM Traffic Light Beam Bending question "This activity was not confusing" showing students doing very well (expecting to receive an "A") in the class generally rated this activity higher than students doing poorly. As can be seen by the error bars, using pair-wise t-tests, the difference between students expecting an " $\mathrm{A}$ " and the other two groups are statistically significant $(\mathrm{t}=2.99, \mathrm{p}<0.01, \mathrm{t}=2.75, \mathrm{p}<0.01$ respectively). The significant aspect of this data is that student's perceived grade did have an effect on the student responses on the ALP surveys.

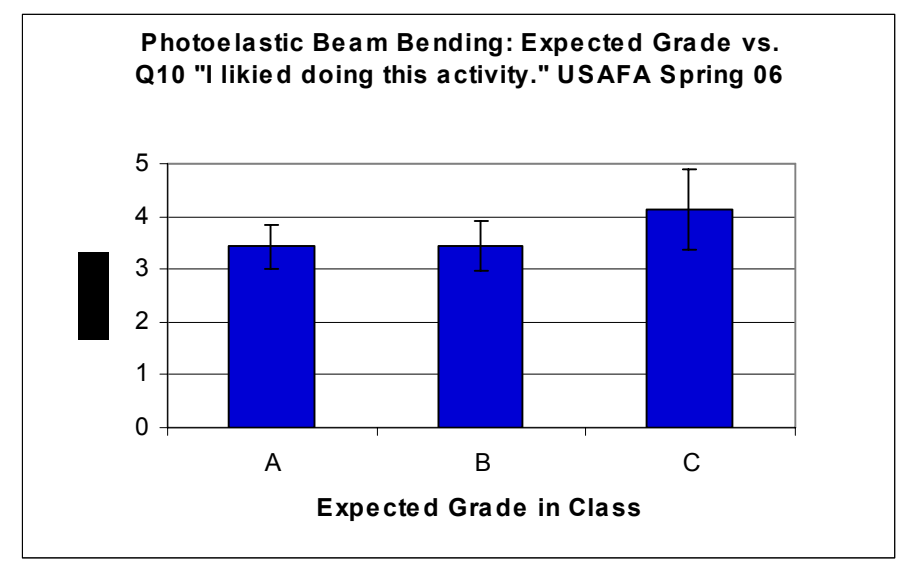

Figure 16: Expected grade v.s. Survey question 10, "I liked doing this activity." USAFA Spring $06(\mathrm{n}=28,21,8$ respectively) 


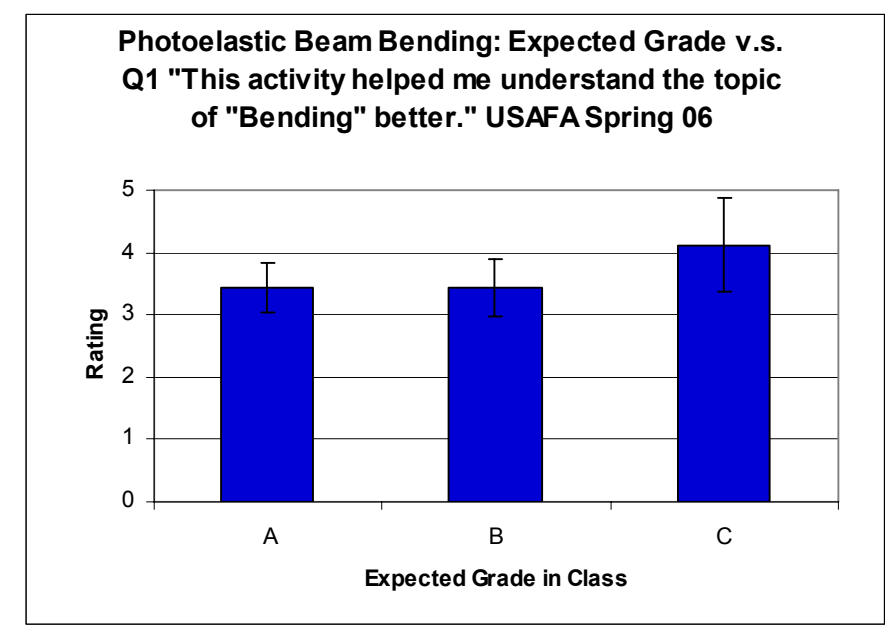

Figure 17: Expected grade v.s. Survey question 1, "This activity helped me understand the topic of "Bending” better." USAFA Spring 06 ( $\mathrm{n}=28,21,8$ respectively)

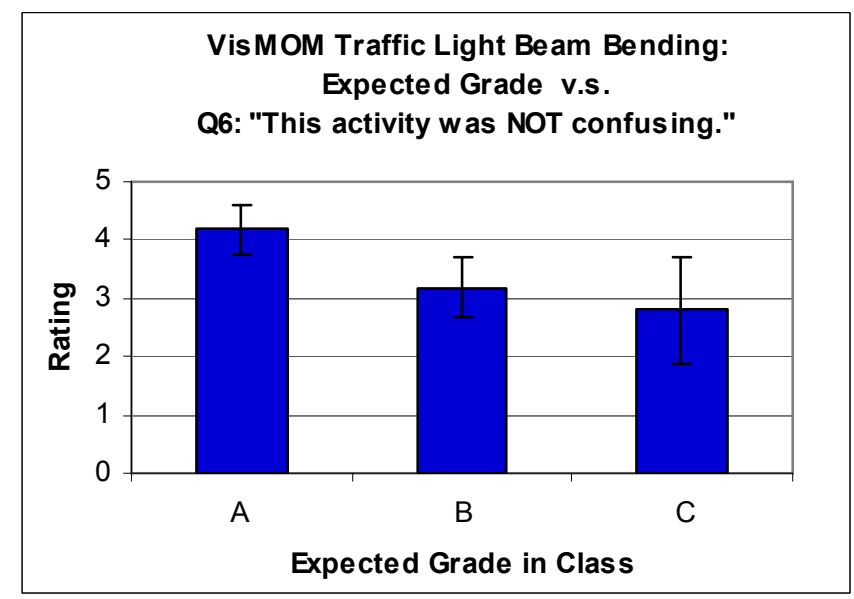

Figure 18: Expected grade v.s. Survey question 6, "This activity was NOT confusing." USAFA Spring $06(\mathrm{n}=22,16,5$ respectively)

\subsection{Student Assessment Results Correlated with Learning Styles}

The correlation of learning styles with student surveys of the ALPs is important for determining how ALPs affect different learning styles. Figures 19-22 show students' opinions correlated with their learning styles. The photoelastic beam bending ALP is an example of an ALP that is equally effective across the various learning styles. The only statistically significant differences were observed for global / sequential and sensor / intuitor learners for a few survey questions (Figure 19 and Table 6 for questions 6, 8, 10).

As can be seen in Figure 19 there were no differences in opinion between global and sequential learners for the VisMOM traffic light ALP. Figure 20 shows the correlations between the "active" and "reflective" learners and their perceptions of this ALP. Active and reflective learners did not have different opinions. Intuitive and sensing learners' opinions did differ significantly on a few survey questions (Figure 21). Intuitive learners found this ALP much more effective for learning (question 7) and more useful than the sensing learners (question $8)(t=3.65, p<0.01$ and $t=3.13, p<0.05)$. Intuitive learners also felt it increased their interest in 
mechanic concepts more (question 9) and liked the activity more than sensing learners (question 10) $(\mathrm{t}=2.48, \mathrm{p}<0.05$ and $\mathrm{t}=2.48, \mathrm{p}<0.05)$

While not statistically significant, in general visual learners were much more positive about the VisMOM traffic light ALP than verbal learners. The current sample contained relatively few verbal learners. This finding is not entirely surprising given the highly visual and interactive nature of this ALP. Visual learners felt that the VisMOM Traffic Light ALP increased their interest in mechanics more than the verbal learners (Figure 22, question 9) $(t=3.57, p<0.01)$. This ALP is a great complement to standard lectures, which appeals more to verbal over visual learners. There is some statistical difference in the effects of the ALPs based on differences in learning styles. These differences give insights for where the ALPs could be improved. Overall the ALPs are very effective across all learning styles.

Table 7: VisMOM traffic Light of Survey Questions

1. This activity helped me understand the topic of "Bending" better.

2. I plan to use the VisMOM software to help me study or do homework later in this course.

3. This activity will help me do future bending homework or exam problems.

4. This activity helped me understand bending in a conceptual manner.

5. This activity will help me on the next exam.

$6^{*}$. This activity was confusing.

7. I believe this activity was more effective than normal homework from the text.

$8^{*}$. The activity was a waste of time.

9. This activity increased my interest in mechanics concepts (like axial, torsion and bending).

10. I liked doing this activity.

*Reversed scored

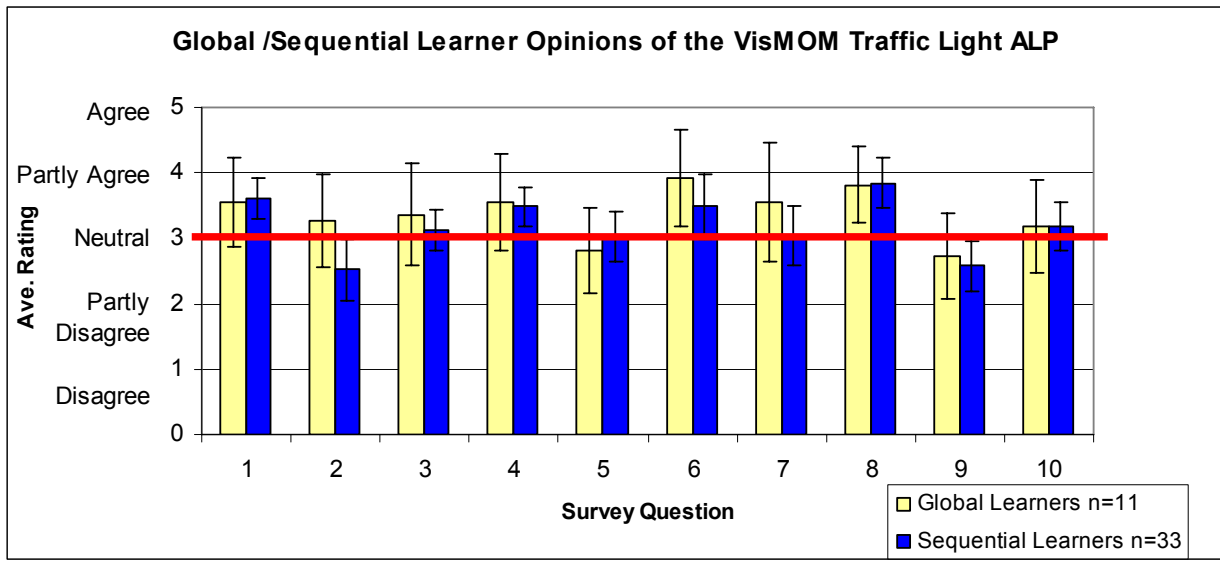

Figure 19: Influence of global and sequential learning styles on their opinions of the photoelastic beam ALP. USAFA Spring 06 


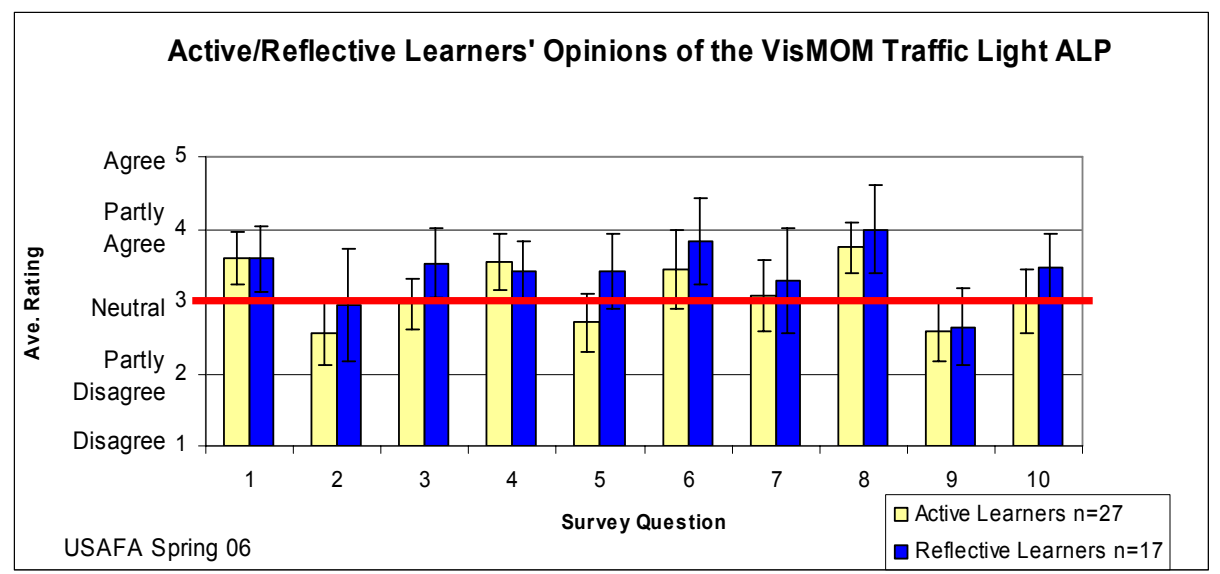

Figure 20: Comparison of active and reflective learners' opinions of the VisMOM traffic light ALP USAFA Spring 06.

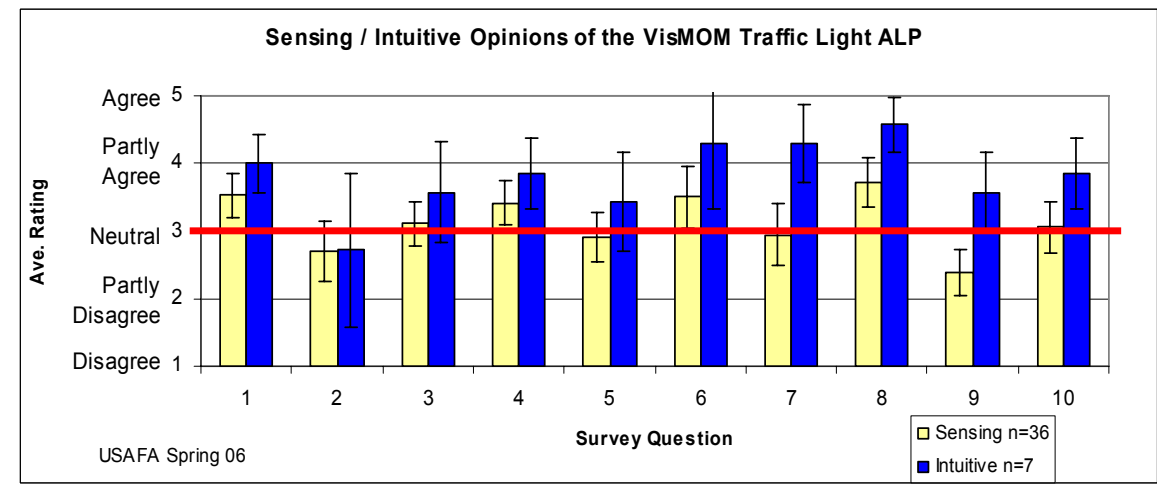

Figure 21: Comparison of sensor and intuitor learners' opinions of the VisMOM traffic light ALP. (Error bars are 2 standard errors) USAFA Spring 06

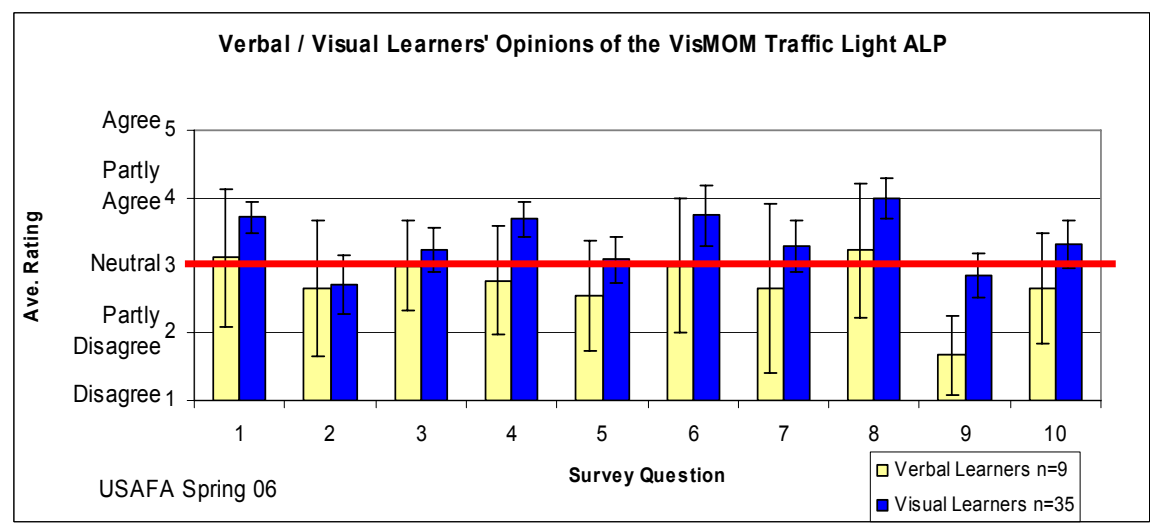

Figure 22: Comparison of verbal and visual learners' opinions of the VisMOM traffic light ALP.

(Error bars are 2 standard errors) USAFA Spring 06

\subsection{Student Assessment Results Correlated with MBTI}

MBTI was used to assess the influence of personality types on the students' opinions of the ALPs. MBTI was correlated with the survey results from the Photoelastic Beam and VisMOM Traffic Light ALP. Figures 23-25 show representative example survey results correlated with 
MBTI. In general there were few differences across personality types. The photoelastic beam activity was completed in groups of two to four students and therefore it was not unexpected that extrovert students would be more positive about the activity than introverts. As can be seen in Figure 23, the assessment does not validate this hypothesis. ALPs appeal to students' with a wide range of personality types.

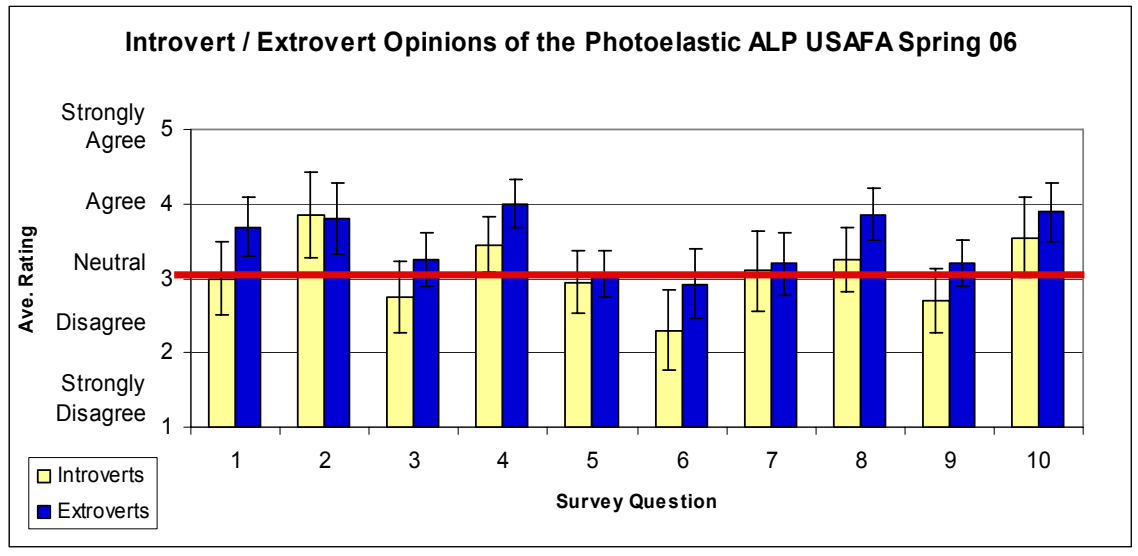

Figure 23: No significant differences were observed between introverts' and extroverts' opinions. USAFA Spring 06 ( $\mathrm{n}=20$ and 36 , respectively)

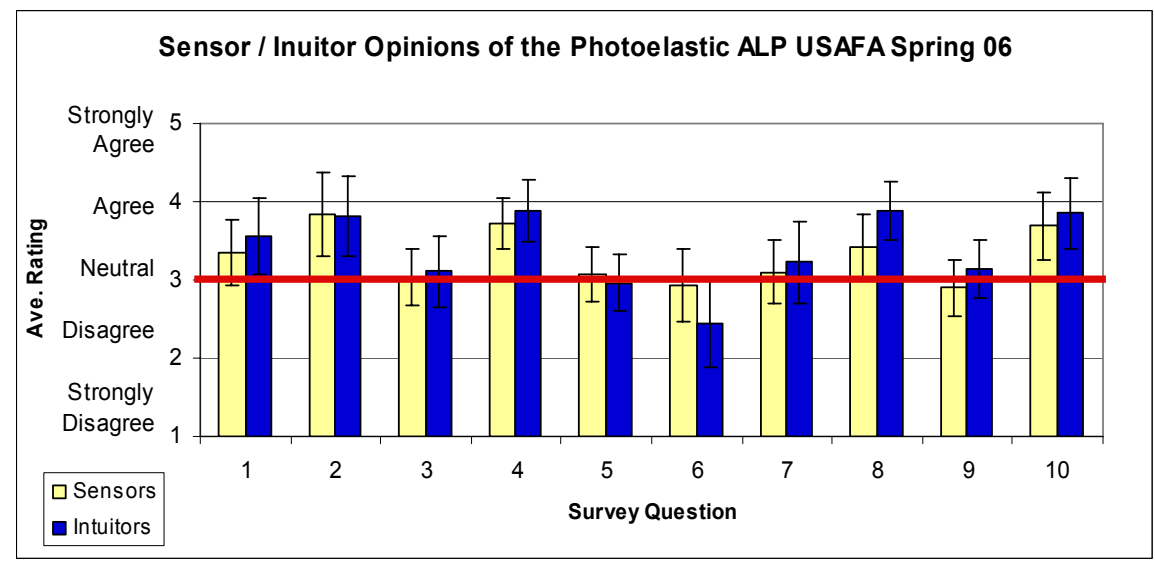

Figure 24: Students' opinions did not vary depending if they were sensors or intuitors. USAFA Spring 06 ( $\mathrm{n}=29$ and 27 , respectively)

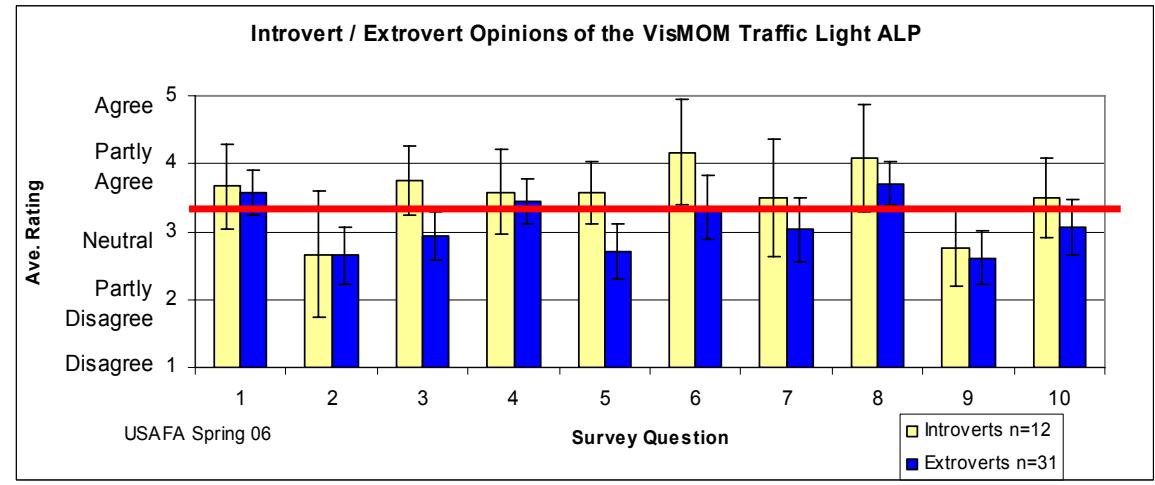

Figure 25: Introvert / Extrovert correlations with student survey. USAFA Spring 06 


\section{Assessment Results: Question 3}

Research Question 3: What measures are important for a robust assessment strategy for the evaluation of questions 1 and 2 ?

To evaluate this research question the relevant data collected included student surveys across multiple types of institutions, surveys across course sections, pre and post quizzes, final exam results and a focus group. Between fall 2005 and summer 2006 sixteen sets of ALPs surveys, five pre and post quizzes, two final exam results and a focus group data set were assessed (Table 2). The following are representative samples of the data sets that provide additional information about the importance of the various instruments.

\subsection{Assessment Surveys}

The largest set of data collected was surveys, which provide significant insights into the students' perceived needs. The Brittle and Ductile Failure ALP was evaluated at ACC in the fall of 2005 with four students and at UT in spring 2006 with twenty-eight students. At both schools, the students overwhelmingly expressed that the activity helped them to better understand brittle failure (Table 8, Figure 26, Table 9). This result is encouraging, as failure modes are known to be a difficult concept. In understanding failure, students at UT generally agreed that it helped them, but students at ACC were more mixed in their opinions. The ACC experimental population did have a small sample size, but this difference is worth investigating. Students at both schools were more neutral regarding their ability to draw stress elements after the activity. Students at both Table 8: List of Survey Questions for Brittle and Ductile Failure Student Survey

1. This activity helped me to better understand brittle failure.

2. This activity helped me to better understand ductile failure.

3. The activity was a waste of time.

4.* The activity was NOT enjoyable.

5. I am better at drawing stress elements.

6. I would like more hands-on activities in class.

*Reversed Scored schools thought the activity was worthwhile, would like to see more hands-on activities in class, and thought it was enjoyable.

Table 9: ACC Fall 2005 Student Assessment of Brittle and Ductile Failure ALP

\begin{tabular}{|c|c|c|c|c|}
\hline Question & $\begin{array}{c}\text { Strongly } \\
\text { Disagree }\end{array}$ & Disagree & Agree & $\begin{array}{c}\text { Strongly } \\
\text { Agree }\end{array}$ \\
\hline $\begin{array}{c}\text { This activity helped me to better } \\
\text { understand brittle failure. }\end{array}$ & 0 & 0 & 3 & 1 \\
\hline $\begin{array}{c}\text { This activity helped me to better } \\
\text { understand ductile failure. }\end{array}$ & 0 & 2 & 1 & 1 \\
\hline The activity was a waste of time. & 1 & 2 & 1 & 0 \\
\hline The activity was enjoyable. & 1 & 0 & 2 & 1 \\
\hline I am better at drawing stress elements. & 0 & 2 & 2 & 0 \\
\hline $\begin{array}{c}\text { I would like more hands-on activities in } \\
\text { class. }\end{array}$ & 0 & 1 & 1 & 2 \\
\hline
\end{tabular}


Students at USAFA in the spring of 2006 were surveyed for their opinion of the "Identify Items under Combined Loads" ALP (Table 10). Overall Figure 27 shows that there are a few significant differences in responses from the four different sections. These differences are mainly between section 2 and section 6 . In general the students seem ambivalent regarding whether the activity helped them understand combined loading better (question 1). They generally thought that the activity was preferable to only seeing an example in class and that it was more effective than a standard homework assignment (questions 2 and 3). However, the activity did not appear to increase their interest in mechanics and they were not convinced it would help them prepare for the exam (questions 4 and 5).

\section{Surveys provide}

generalizable information and are quick to implement and evaluate. They give less insight into why students do not like certain aspects of the ALPs. They also do not provide direct evidence that the students are learning more. Students' learning can be more directly measured with quizzes and exam questions.

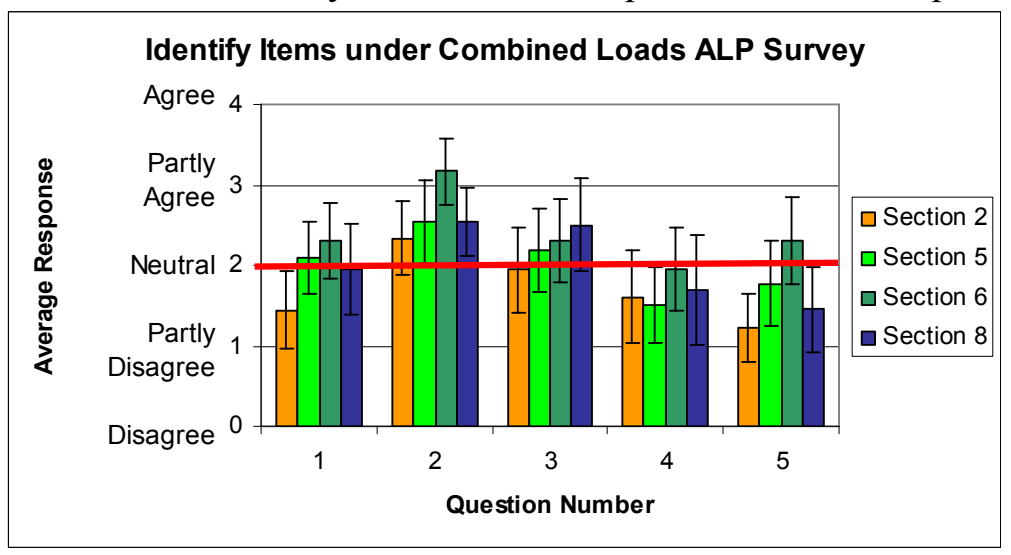

Figure 27: Student Opinions of the "Identify Items under Combined Loads" ALP by section. (Error bars are two standard errors. $\mathrm{n}=18,22,23,21$ and 20 respectively). 


\subsection{Assessment Quick Quizzes and Final Exam Results}

Quizzes are used as a way of directly measuring students' knowledge before and after experiencing an ALP or traditional lecture. A "Quick Quizzes" was administered immediately before and after a VisMOM module was used. The control group was formed by administering the same quick quiz before and after a classic lecture style class. The results tabulated in Table 11 were normalized to indicate the average score (percentage) achieved with and without the multimedia. Note that for each of the three VisMOM subjects (Torsion, Bending and Combined Loading), the students had greater quiz score improvement using the multimedia than they did from traditional lecture. This data is based on over 100 data points. Also, the same two professors were giving the traditional lectures as were using the VisMOM, which removes individual professor's effectiveness as a "noise" variable.

Table 11: Quick Quiz Results

\begin{tabular}{|l|l|c|c|c|}
\hline $\begin{array}{l}\text { VisMOM } \\
\text { Subject }\end{array}$ & \multicolumn{1}{|c|}{ Description of the Group } & $\begin{array}{c}\text { Average Quiz } \\
\text { Score Before }\end{array}$ & $\begin{array}{c}\text { Average Quiz } \\
\text { Score After }\end{array}$ & $\begin{array}{c}\text { Percent } \\
\text { Improvement }\end{array}$ \\
\hline \multirow{2}{*}{ Torsion } & Students who saw the module & $80 \%$ & $100 \%$ & $20 \%$ \\
\cline { 2 - 5 } & Students who did NOT see the module & $62 \%$ & $71 \%$ & $9 \%$ \\
\hline \hline \multirow{2}{*}{ Bending } & Students who saw the module & $27 \%$ & $69 \%$ & $42 \%$ \\
\cline { 2 - 5 } & Students who did NOT see the module & $43 \%$ & $76 \%$ & $33 \%$ \\
\hline \hline \multirow{2}{*}{$\begin{array}{l}\text { Combined } \\
\text { Loading }\end{array}$} & Students who saw the module & $35 \%$ & $93 \%$ & $58 \%$ \\
\cline { 2 - 5 } & Students who did NOT see the module & $21 \%$ & $75 \%$ & $54 \%$ \\
\hline
\end{tabular}

Finally, in an attempt to obtain a more longitudinal assessment of learning increases facilitated by VisMOM, a specific final exam question, which tested content covered either by VisMOM or by traditional lecture, was given. As shown in Table 12, the percentage of students who correctly answered the exam question was significantly greater (45\%) for those who used VisMOM compared with those who did not (28\%).

Table 12: Final Exam Results

\begin{tabular}{|l|c|c|}
\hline & $\begin{array}{l}\text { Number of } \\
\text { Data Points }\end{array}$ & $\begin{array}{l}\text { \% of Students Correctly } \\
\text { Answering the Exam Prob. }\end{array}$ \\
\hline Students Receiving the Module & 40 & $45 \%$ \\
\hline Students NOT Receiving the Module & 635 & $28 \%$ \\
\hline Percent Difference & & $23 \%$ \\
\hline
\end{tabular}

Short quizzes and exam questions provide a quantitative measure of students learning that can not be obtained through surveys. Quizzes and exam questions do not evaluate the students' opinions of the activities and give limited insight into how an ALPs may need to be improved. 


\subsection{Focus Group Results}

To provide additional qualitative information about students' perceptions of the ALPs, an external assessment expert at UT conducted a focus group in spring 2006. The focus group began with a short survey to get students thinking about their experiences. It consisted of their perceived effectiveness of the three ALPs used in class and asked them to list the most difficult topics in mechanics of materials and machine elements. On average students found the activities to be useful or somewhat useful (Figure 28).

During the focus group the facilitator asked a series of questions to get the students talking. Students made a number of interesting comments that gave guidance on where the activities and their implementation could be improved. Students wanted more ALPs in their class and wished they had been used in previous classes. Students believed ALPs should be included for every topic. Interestingly, students liked the brittle and ductile failure activity but said that activity was not challenging enough for a machine elements class. In general, they felt the activities needed to be challenging. They also believed this set of activities helped improve their conceptual understanding but not their analytical. They also believed activities could be created to assist with both types of understanding.

Students were also insightful about the effects the professor has on a class. One student commented that understanding has more to do with the professors than with the activities and felt the results would be different with a different professor.

For this particular class, all of the activities had been done individually so the topic of group ALPs was discussed. Surprisingly, the students liked group work but felt the activities would be less effective in a group. Student comments included, "It's building your intuition, you can't convey that in a group setting." and "[pairs/group work] defeats the purpose of hands-on." Focus groups

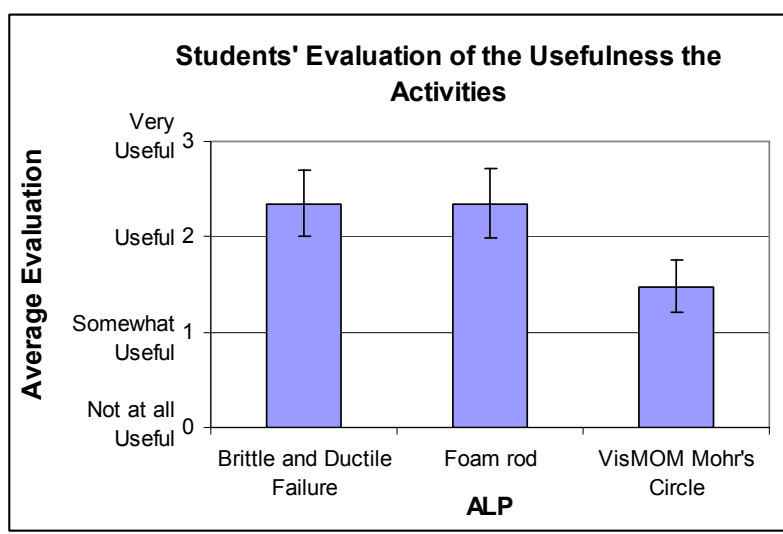

Figure 28: Students' perception of the usefulness of each ALP. provide the opportunity to gather students' reaction to the overall ALP approach. Much insight into how to better implement and where additional ALPs are needed can be gained through the use of a focus group. Focus groups provide another piece of complementary information in the assessment process.

\section{Discussion: Addressing the Research Questions}

\subsection{Question 1: Are the ALPs effective for improving learning?}

ALPs are an effective method to improve learning. Overall, the effects of the ALPs are very positive. The impact on student learning is quantitatively shown by the pre and post quiz results. The pre and post quiz data shows that the average improvement of groups receiving the ALP was greater than the groups receiving standard lectures, indicating that students are learning more 
with the ALPs. Students are generally positive about the activities and desire more activities be added to their coursework. This indicates the students enjoy the activities and feel they are learning from them. ALPs give professor another avenue to incorporate active learning in their classrooms.

\subsection{Question 2: Are the effects of the ALPs different, based on student characteristics?}

The ALPs are effective across a range of student characteristics. Overall, the activities work well for a diverse set of learning styles, personalities and demographics. The ALP evaluations included a few statistically significant results based on correlations to learning styles, personality types, and students' performance in class. These measures provide insights into possible improvement in the ALPs to better meet the needs of all students. ALPs appeal to and work well for a variety of learning styles and personal types.

\subsection{Question 3: What measures are important for a robust assessment strategy for the evaluation of questions 1 and 2?}

As shown by this research, a broad range of measures are required to show the effects of the ALPs on a spectrum of outcomes. These measures include student opinion surveys, pre / post quizzes, exam questions, and focus groups. Each of these assessment measures provides different but complementary information about the activities. In many cases, if only one of the measures had been used, the results would have been inconclusive or, possibly, uninformed. Students' opinions give feedback on their evaluation of an activity but do not provide a complete picture. Occasionally, for example in the case of the Foam Beam ALP, it is shown that the ALPs improve student learning, while at the same time students are indifferent to the value of the ALP. Focus group data provides additional information that is not available through other assessment methods.

In addition, if the ALPs are expected to be deployed across a broad range of institutions, they must be tested in a number of different situations. Variations across institution are observed. Teaching standards and expectations of hands-on activities in USAFA's classes are generally very high. USAFA currently uses a variety of active learning approaches and their classes tend to be small. This landscape sets very high student expectations for an activity, which may explain why student opinions at USAFA tend to be lower than at UT. Overall, we found that the measures developed for our studies worked very effectively at providing different insights into the effectiveness of the ALPs.

\section{Conclusion and Future Work}

ALPs are an effective way to bring active learning into an engineering class and add a tremendously powerful tool to the engineering educator's tool chest. ALPs can be used to seamlessly incorporate active learning into a traditional lecture. As any engineering educator attempts to incorporate new approaches into their classroom, educators need to assess their course design with appropriate measures, including student opinions, focus groups, their observations and quantitative measures of learning such as quizzes and exam questions. Educators need to also consider influence from various demographics, learning styles, and personality types. The types of learning environments and approaches the students are familiar 
with will also influence the results. Occasionally, a quiz or exam question shows an approach improves learning but student surveys indicate that students do not find the approach effective.

A total of twenty-eight hands-on activities have been developed. This paper evaluates seven of the twenty-eight using a combination of student opinion surveys, pre/post quizzes, focus groups and a concept inventory. These activities were implemented into lecture classes in three different types of higher learning institutions (a community college, a teaching university and a research university). In general, students were positive about the activities and felt their learning experience was improved. Measurable increases in learning as compared to a standard lecture are observed.

In addition, demographic information, personality and learning styles were also recorded. Most ALPs work well for a variety of personalities and learning styles. However, a few students' opinions are statistically different based on learning style. The activities also work well for a variety of demographic factors. In addition it is shown that for some of the activities the students' perceived performance in the class directly correlated with their opinion of the activity. In this case students who were very well in the class were less confused by the ALP than students doing less well. Our results suggest it is important to take into account a diverse set of measures when evaluating new learning approaches. These measures include demographic information and learning styles.

Future work will include continued improvements to developing, assessing, and implementing ALPs that improve the student learning process. Future work is needed to continue to collect and analyze larger data sets to further assess the ALPs. The next step is to disseminate the ALPs and the methodology for creation of future ALPs to the education community. ALPS are shown to be effective for improving learning, students feel they are effective and students desire more active learning activities in their classes. ALPs provide a powerful tool for professor to increase active learning.

\section{Acknowledgements}

The work is made possible, by a National Science Foundation grant DUE-0442614, and in part by the University of Texas at Austin College of Engineering and the Cullen Trust Endowed Professorship in Engineering No. 1. The authors would also like to thank Ms. Emily Clauss and Ms. Jing-Jing Zhou for their assistance in the data entry, building the ALPs and preliminary data analysis. Also, support is acknowledged from the Institute for Information and Technology Applications (IITA) at the US Air Force Academy. In addition, we acknowledge the support of the Department of Engineering Mechanics at the U.S. Air Force Academy as well as the financial support of the Dean's Assessment Funding Program. Any opinions, findings, or recommendations are those of the authors and do not necessarily reflect the views of the sponsors.

\section{Bibliography}

[1] Prince, M., "Does Active Learning Work? A Review of the Research," Journal of Engineering Education, Vol. 93, no. 3, pp. 223-231, July, 2004. 
[2] Aglan, H.A. and Ali, S.F., "Hands-on Experiences: An Integral Part of Engineering Curriculum Reform," Journal of Engineering Education, Vol. 85, no. 4, pp. 327-330, Oct., 1996.

[3] Bonwell, C.C., "Active Learning and Learning Styles," Active Learning Workshops Conference, Content available at http://www.active-learning-site.com/vark.htm, 1998.

[4] Bridge, J., "Incorporating Active Learning in an Engineering Materials Science Course," Proceedings, ASEE Annual Conference and Exposition, 2001.

[5] Carlson, L.E., "First Year Engineering Projects: An Interdisciplinary, Hands-on Introduction to Engineering," Proceedings of the ASEE Annual Conference and Exposition, pp. 2039-2043, 1995.

[6] Catalano, G.D. and Tonso, K.L., "The Sunrayce '95 Idea: Adding Hands-on Design to an Engineering Curriculum," Journal of Engineering Education, pp. 193-199, July, 1996.

[7] Dennis, S., Bowe, M., Ball, J., and Jensen, D.D., "A Student-Developed Teaching Demo of an Automatic Transmission," Proceedings of the ASEE Annual Conference and Exposition, Albuquerque, NM, June, 2001.

[8] Feland, J.M. and Fisher, C.A., "Cramming Twenty pounds into a Five-Pound Bag: Increasing Curricular Loads on Design Students and Enjoying it!," Proceedings of the ASEE Annual Conference and Exposition, Montreal, Quebec, Canada, June, 2002.

[9] Kresta, S.M., "Hands-on Demonstrations: An Alternative to Full Scale Lab Experiments," Journal of Engineering Education, Vol 87, no. 1, pp. 7-9, Jan., 1998.

[10] Otto, K., Wood, K.L., Murphy, M.D., and Jensen, D.D., "Building Better Mousetrap Builders: Courses to Incrementally and Systematically Teach Design," Proceedings of the ASEE Annual Conference and Exposition, Seattle, WA, June, 1998.

[11] Regan, M. and Sheppard, S., "Interactive Multimedia Courseware and the Hands-on Learning Experience: An Assessment," Journal of Engineering Education, pp. 123-131, April, 1996.

[12] Shakerin, S. and Jensen, D.D., "Enhancement of Mechanics Education by Means of Photoelasticity and the Finite Element Method," International Journal of Mechanical Engineering Education, Oct., 2001.

[13] Wood, K.L., Jensen, D.D., Bezdek, J., and Otto, K., "Reverse Engineering and Redesign: Courses to Incrementally and Systematically Teach Design," Journal of Engineering Education, Vol. 90, no. 3, pp. 363374, July, 2001.

[14] Wood, J.J. and Wood, K.L., "The Tinkerer's Pendulum for Machine System's Education: Creating a Basic Hands-On Environment with Mechanical Breadboards," Proceedings of the ASEE Annual Conference and Exposition, St. Louis, MO, June, 2000.

[15] Jensen, D.D. and Bowe, M., "Hands-On Experiences to Enhance Learning of Design: Effectiveness in a Reverse Engineering / Redesign Context When Correlated with MBTI and VARK Types," Proceedings of the ASEE Annual Conference and Exposition, Charlotte, NC, June, 1999.

[16] Jensen, D., Wood, J. and Wood, K., "A Design Methodology for Hands-on Classroom Experiences," Proceedings of the ASEE Annual Conference and Exposition, June, 2004.

[17] "The Research Agenda for the New Discipline of Engineering Education," Journal of Engineering Education, Vol. 95, No. 4, October 2006.

[18] Kerns, S.E.,'Keeping Us on the Same Page," Journal of Engineering Education, Vol. 94, no. 2, pp. 205, April, 2005.

[19] Lohmann, J.R., "Building a Community of Scholars: The Role of the Journal of Engineering Education as a Research Journal," Journal of Engineering Education, Vol. 94, no. 1 pp. 1-6 Jan., 2005.

[20] Linsey, J., Cobb, B., Jensen, D., Wood, K., and Eways, S., "Methodology and Tools for Developing Hands-on Active Learning Activities," Proceedings of 2006 American Society for Engineering Education Annual Conference, Chicago, IL, 2006.

[21] Jung, C.G., Psychological Types, Volume 6 of the Collected Works of C.G. Jung, Princeton University Press, 1971. (Original work published in 1921).

[22] Kersey, D. and Bates, M., Please Understand Me, Del Mar: Prometheus Press, 1984.

[23] McCaulley, M.H., "The MBTI and Individual Pathways in Engineering Design," Engineering Education, Vol. 80, pp. 537-542, July/Aug., 1990.

[24] Felder, R. M., and Soloman, B. A., Index of Learning Styles, <http://www.ncsu.edu/felderpublic/ILSpage.html>, accessed January 10, 2007 